\author{
Contato \\ Faculdade de Ciências Humanas e Sociais \\ Campus de Franca \\ Av. Eufrásia Monteiro Petráglia, 900 \\ 14409-160 - Franca - São Paulo \\ memiliagranduque@gmail.com
}

\section{INSTRUÇÕES PARA \\ A BOA ESCRITA DA HISTÓRIA NA ESPANHA (SÉCULOS XVI - XVII)}

\section{- Maria Emília Granduque José*}

Universidade Estadual Paulista Júlio de Mesquita Filho

Franca - São Paulo - Brasil

\title{
Resumo
}

Entre os séculos XVI e XVII, o saber histórico é enriquecido na Espanha não apenas com a produção de crônicas que reportam as novidades relativas ao Novo Mundo, mas também com tratados elaborados com a finalidade de prescrever regras e diretrizes para a promoção de uma escrita correta e apurada sobre o passado. Tendo em vista que as crônicas não deixam de expor, em seus prólogos e dedicatórias, conselhos a respeito da boa maneira de registrar os acontecimentos, o objetivo deste artigo é analisar esses dois gêneros, a fim de examinar em que medida ajudaram a fixar um mesmo saber a respeito da escrita da história. Em outras palavras, partindo tanto de crônicas quanto de tratados de história, a proposta deste trabalho é examinar como os letrados espanhóis dessa época dissertaram sobre o seu ofício.

\section{Palavras-chave}

Escrita da história - tratados de história - crônicas - Espanha - séculos XVI e XVII.

* Doutora em História Cultural pela Universidade Estadual de Campinas - Unicamp e pósdoutoranda em História pela Universidade Estadual Paulista "Júlio de Mesquita" - Unesp campus de Franca com bolsa da Fapesp (processo 2017/22523-6). Membro do projeto temático "Escritos sobre os Novos Mundos: uma história da construção dos valores morais em língua portuguesa", financiado pela Fundação de Amparo à Pesquisa do Estado de São Paulo - Fapesp, (processo 2013/14786-6) e do Laboratório de Estudos Americanos - LEA da Unicamp. Autora do livro A Malinche dos cronistas (Prismas, 2016) e de estudos que versam sobre a história da América colonial e da cultura ibero-americana. 

CENTURIES)

\author{
Contact \\ Faculdade de Ciências Humanas e Sociais \\ Campus de Franca \\ Av. Eufrásia Monteiro Petráglia, 900 \\ 14409-160 - Franca - São Paulo \\ memiliagranduque@gmail.com
}

\author{
- Maria Emília Granduque José \\ Universidade Estadual Paulista Júlio de \\ Mesquita Filho \\ Franca - São Paulo - Brazil
}

\begin{abstract}
Between the 16th and 17th centuries, historic knowledge is enriched, in Spain, not only with the writing of chronicles that report news pertaining to the New World, but also with the treatises drawn up with the purpose of prescribing rules and guidelines for the promotion of a correct and accurate writing about the past. Bearing in mind that the chronicles do not cease to expose, in their prologues and dedications, advice regarding the proper way to record events, the objective of this article is to analyze these two genres, in order to examine the extent to which they helped to secure a shared knowledge about the writing of history. In other words, taking as starting point chronicles as well as treatises of history, the proposal of this work is to examine how the Spanish scholars of the time wrote about their métier.
\end{abstract}

\title{
Keywords
}

Writing of history - treatise of history - chronicle - Spain $-16^{\text {th }}$ and $17^{\text {th }}$ centuries. 
No final do segundo capítulo do livro El ingenioso hidalgo don Quijote de la Mancha, de Miguel de Cervantes, o personagem narrador, ao contar o desfecho do capítulo intitulado "Donde se concluye y da fin a la estupenda batalla que el gallardo vizcaíno y el valiente manchego tuvieron", interrompe a sua narrativa por lhe faltarem dados sobre o final dessa aventura vivida pelo cavaleiro andante que dá nome à história. Confessa que a obra consultada para contar a sua versão estava incompleta e impossibilitava que ele e o seu leitor soubessem a conclusão do episódio. Se, por um lado, ele lamenta que uma "história tão bela" estivesse manca pela ação do tempo, tido como "devorador e consumidor de todas as coisas", por outro, o narrador tinha a esperança de encontrar algum registro escrito ou vivo na "memória das pessoas de sua aldeia" que lhe desse notícia sobre o fim dessa aventura' (CERVANTES SAAVEDRA, 2015, p. 50). Julgava que não deveriam ser completamente desconhecidos os feitos de "reparar afrontas, socorrer viúvas e amparar donzelas"2 (CERVANTES SAAVEDRA, 2015, p. 50) que empreendeu o cavaleiro dom Quixote no tempo em que percorreu, ao lado do seu escudeiro Sancho Pança, os vales e as montanhas da região da Mancha.

Ao que parece, o narrador não se enganou quando pensou essa matéria. Conta que, estando na cidade de Alcalá de Toledo, encontrou um vendedor de cadernos e papéis velhos que trazia entre os seus folhetos um texto grafado em caracteres árabes. Com o auxílio de um dos muitos mouros que passavam por ali, conseguiu traduzir o título da presente obra, que dizia Historia de dom Quixote de la Mancha, escrita por Cide Hamete Benengeli, historiador árabe e, posteriormente, obteve a conversão completa para o castelhano. À primeira vista, o narrador pôde constatar que os personagens citados eram os mesmos da primeira história que havia consultado e que as ilustrações refletiam os mesmos gestos descritos na cena da batalha. Mas, no que toca aos elogios direcionados ao cavaleiro dom Quixote, excessivos na primeira versão manuseada, não deixou de observar que o historiador árabe como que de propósito manteve silêncio ${ }^{3}$ (CERVANTES SAAVEDRA, 2015, p. 52). Prática condenada pelo personagem, na medida em que atribuía aos historiadores o dever de serem "minuciosos, verdadeiros e nada apaixonados" e

\footnotetext{
1 CERVANTES SAAVEDRA, Miguel de. El ingenioso hidalgo don Quijote de la Mancha. Edição de Enrique Suárez Figaredo. Lemir 19. Conmemoración del IV Centenario de la Segunda Parte del Quijote, 2015, p. 50. Todas as citações foram traduzidas para o português.

2 Idem, p. 50.

3 Ibidem, p. 52.
} 
de saber que "o interesse ou o medo, o rancor ou a afeição" os fariam se afastar "do caminho da verdade, cuja mãe é a história, êmula do tempo, depósito de ações, testemunha do passado, exemplo e aviso do presente, advertência do futuro"4 (CERVANTES SAAVEDRA, 2015, p. 52).

Tal passagem descrita pelo narrador no início da segunda parte das aventuras do El ingenioso hidalgo don Quijote de la Mancha, publicadas na Espanha entre 1604 e 1605, embora se refira ao personagem fictício da obra de Miguel de Cervantes, repercute certos valores apreciados no século XVI e XVII acerca do rigor histórico daqueles que se comprometiam a narrar o passado. Não foram poucos os escritores espanhóis que definiram em suas obras as regras necessárias para se escrever a história tanto na esfera oficial, pelos cronistas e historiadores régios, quanto no domínio não oficial em que trabalhava grande parte dos autores. ${ }^{5}$ Nas crônicas que relatam as novidades sobre o Novo Mundo, a reflexão em torno do fazer histórico fica evidente especialmente nas páginas iniciais, nomeadamente nos prólogos e nos proêmios dessas obras, espaços similares em que os autores estabelecem um diálogo com o seu leitor explicando-lhe não só as razões que o levaram a escrever, mas também o estilo e o método que haviam conduzido a sua escrita. Mais precisamente, são nesses espaços introdutórios que os cronistas espanhóis anunciavam os conteúdos abordados e dissertavam sobre as formas como o seu texto deveria ser apresentado ${ }^{6}$ (PORQUERAS MAYO, 1957, p. 87).

Se cronistas como Bartolomé de Las Casas, Francisco López de Gómora, Diego de Palencia, Juan de Torquemada e Antonio Solís dissertavam acerca das regras que deveriam pautar as suas narrativas, alguns tratadistas, especialmente Juan Páez de Castro, Luis Cabrera de Córdoba e Jerónimo de San

\footnotetext{
${ }^{4}$ Ibidem, p. 52.

5 Cf. CUESTA DOMINGO, Mariano. Los cronistas oficiales de Índias. De López de Velásco a Céspedes del Castillo. Revista Complutense de Historia de América, vol. 33, Madri, 2007, p. 115-150. ISSN 1132831. Disponível em: <http://revistas.ucm.es/index.php/RCHA/>. Acesso em: 23 out. 2016. DOI: http://revistas.ucm.es/index.php/RCHA/article/view/29626 e GONZÁLEZ BOIXO, José Carlos. Hacia una definición de las crónicas de Indias. Anales de Literatura Hispanoamericana, n. 28, Espanha, 1999, p. 227-238. ISSN 0210-4547. Disponível em: https://dialnet.unirioja.es/revista/75/A/1999. Acesso em: 13 jun. 2015. DOI: https://dialnet.unirioja.es/servlet/articulo?codigo=52307.

6 Para Alberto Porqueras Mayo, o escritor espanhol se vale do prólogo como "vehículo expresivo con características propias, capaz de llenar las necessidades de la function introdutiva" do seu livro. Diferente dos séculos anteriores, quando os prólogos cumpriam o papel de dedicatória dos livros, esse autor sustenta que, a partir do século XVI, essa parte passa a ter uma função introdutória da qual o autor utiliza para, entre outras práticas, aconselhar, instruir e orientar seus leitores sobre determinada matéria. PORQUERAS MAYO, Alberto. El prólogo como genero literario. Su estudio en el siglo de oro español. Madri: Consejo Superior de Investigaciones Científicas, 1957, p. 87.
} 
José, buscavam não apenas definir melhor esses critérios da escrita sobre o passado, mas também ampliar o quadro de prescrições relativas à maneira como os historiadores tinham de exercer o seu ofício. Cruzando recomendações comuns às crônicas e aos tratados de história, este estudo tem como alvo explorar as balizas que delimitavam os padrões da escrita da história a partir dos principais aspectos estruturantes de sua produção, a saber, os elementos considerados importantes para a maneira correta de narrar o passado - como a escrita culta, a consulta de fontes e de testemunhos fiáveis e a transmissão verdadeira dos fatos -, bem como os caminhos que deveriam ser evitados pelo historiador, como o uso excessivo de recursos estilísticos que dificultavam a clareza do texto.

Na Historia de las Indias, composta em 1559, o frei dominicano Bartolomé de Las Casas, ao apresentar as razões que o moveram a compor a sua obra, descreve os diversos caminhos seguidos pelos historiadores para reportar o passado. Segundo ele, enquanto muitos letrados utilizavam o texto, valendose de grande eloquência, como meio para conquistar fama e glória pessoais, outros escritores buscavam, a partir da sua produção, agradar aos governantes cumprindo o papel mais de bajuladores do que de historiadores. Prosseguindo com sua explicação, esse religioso retoma as palavras de Diodoro7 para alertar sobre os perigos dessa forma de se fazer história. Assim diz:

Justíssima razão é que os historiadores fossem doutos, espirituais, temerosos e não amplos de suas consciências ou que se orientassem por algum fim ou paixão particular, porque, quando se referem às coisas ocorridas em seus tempos, temem culpar ou desculpar dos maus e execráveis feitos algumas das partes, como alguns têm feito; se culparem ou desculparem olhem muito bem primeiro o que determinam escrever, porque é grande o prejuízo da desculpa de uns e da culpa de outros, para muitos e muitas coisas, nos tempos vindouros (.... ${ }^{8}$ (LAS CASAS, 1986, p. 9).

Las Casas, ao enfatizar que a escrita da história precisa se ater à verdade dos fatos, recomenda ao historiador a não se render aos interesses particulares em detrimento dos compromissos de seu labor. Em outras palavras, o religioso adverte que o escritor, ao narrar os eventos passados, não pode nem se eximir de destacar as boas obras realizadas pelos inimigos nem tam-

\footnotetext{
7 Diodoro Sículo foi um historiador grego que viveu no século I a. C. Deixou como única obra a Biblioteca histórica, um conjunto de livros sobre a história da Grécia e de Roma.

8 LAS CASAS, Bartolomé de. Historia de las Indias, tomo I. Venezuela: Biblioteca Ayacucho, 1986, p. 9.
} 
pouco deixar de condenar as faltas cometidas pelos amigos. ${ }^{9}$ Tendo como alvo ressaltar o caráter pedagógico da história, esse cronista conclui que é pelo conhecimento das virtudes e dos erros que os homens aprendem a se conduzir nos diferentes âmbitos da vida.

Embora Las Casas tenha se ocupado sobretudo em descrever os eventos relacionados à ação dos conquistadores nas Índias, isto é, os embates decorrentes do encontro entre ameríndios e espanhóis na região do México na primeira metade do século XVI, a sua obra ajuda a promover os critérios para a escrita da história que vinham sendo partilhados pelos homens da sua época ${ }^{10}$ (CORTIJO OCAÑO, 1995, p. 220). No prólogo que antecede o texto principal, esse cronista discute dois pontos similares aos aspectos tratados pelos historiadores desse período: de um lado, a utilidade de se conhecer as matérias passadas para que delas se possam tirar lições úteis no futuro; de outro, o modo como essas matérias deveriam ser escritas. Quanto ao primeiro aspecto, o cronista busca mostrar que a história não é apenas a narrativa dos grandes eventos do passado, mas, ainda, o registro das ações empreendidas em outras épocas para oferecer modelos de comportamento aos leitores ${ }^{11}$ (DURÁN BARCELÓ, 1996, p. 167). Já no que se refere ao segundo aspecto, o estilo empregado no texto, Las Casas sugere que a narrativa deve estar amparada em uma escrita clara e inteligível, isto é, em uma escrita livre

\footnotetext{
9 A esse respeito, Edmundo O'Gorman considera que a história nesse período já não era a simples narração dos grandes feitos do passado e tampouco seu objeto era salvá-los do esquecimento. A história como mestra da vida buscava registrar os fatos para que servissem como modelos morais aos seus leitores. O'GORMAN, Edmundo. Cuatro historiadores de Indias. Siglo XVI. México: Sep/Setentas, 1972, p. 226. De forma complementar, José Aragüés Aldaz escreve que se nota nos textos do Renascimento um especial interesse pelos feitos virtuosos tanto dos tempos passados como dos tempos mais próximos a esses escritores, bem como a orientação de que os historiadores deveriam atender à escrita exemplar "más allá de la mera curiosidad por los hechos pretéritos". ARAGUÉS ALDAZ, José. Deus concionator. Mundo predicado y retorica del exemplum en los siglos de oro. Amsterdam: Atlanta, 1999, p. 141.

${ }^{10}$ Refiro-me à arte historiae ou simplesmente arte da história apresentada pelos letrados espanhóis em seus textos com o intuito de fixar regras específicas para o fazer histórico. CORTIJO OCAÑO, Antonio. Creación de una voz de autoridad en Bartolomé de Las Casas: estudio del "prólogo" de la Historia de Indias. Revista Iberoamericana, vol. LXI, n. 170-171, jan.-jun. 1995, p. 291-229, p. 220. ISSN 2154-4794. Disponível em: http://revista-iberoamericana.pitt.edu/ojs/index.php/ Iberoamericana/issue/view/252. Acesso em: 20 nov. 2017. DOI: http://revista-iberoamericana. pitt.edu/ojs/index.php/Iberoamericana/article/view/6405/6581.

${ }^{11}$ DURÁN BARCELÓ, Javier. La teoría historiográfica de Bartolomé de Las Casas. Studia Aurea. In: III CONGRESO DE LA AISO. Actas, vol. 3. Toulouse, 1996, p. 161-168, p. 167. ISBN 84-9215813-1. Disponível em: https://cvc.cervantes.es/literatura/aiso/pdf/03/aiso 333 021.pdf. Acesso em: 15 dez. 2017.
} 
de adornos que possa preservar os propósitos da história, do modo como ele mesmo diz realizar em sua obra. ${ }^{12}$ Para esse religioso, os historiadores não devem supervalorizar a forma do texto em detrimento dos conteúdos apresentados, pois, ao seguirem por este caminho, perderiam o objetivo central da sua obra que é ensinar os seus leitores.

A Historia de las Indias não é a única - entre os textos produzidos sobre a América nos séculos XVI e XVII - a dissertar sobre a concepção da história e a maneira como os historiadores deveriam escrevê-la, já que parte dos escritos acerca dos descobrimentos trazem reflexões breves ou mais densas a respeito do registro do passado. ${ }^{13}$ As considerações deixadas pelo clérigo e historiador Francisco López de Gómora são um exemplo. Nas primeiras páginas da Historia de la conquista de México, datada de 1552, sublinha que a história é necessária para a "memória, aviso e exemplo dos outros mortais"14 " (LÓPEZ DE GÓMORA, 1979, p. 4) à medida que os instrui fornecendo modelos de conduta moral retirados do passado. Com base nessa definição, esse cronista orienta que os historiadores devem sempre escrever com verdade as causas dos eventos e procurar serem mais gerais nos seus relatos, pois a atitude de particularizar os fatos narrados, ocupando-se de um único episódio, pode levá-los a ofender uns e outros personagens ${ }^{15}$ (PRIETO, 2005, p. 22). Já na parte intitulada "Ao leitor", correspondente ao prólogo dessa obra, dedica-se a informar sobre o estilo adotado no seu texto, dizendo ter elaborado uma narrativa "leve e plana", com "ordem concertada e igual", "capítulos curtos", "sentenças claras, ainda que breves", buscando dizer "as coisas conforme se passaram"16 (LÓPEZ DE GÓMORA, 1979, p. 1). Alerta, ainda, que

\footnotetext{
${ }_{12}$ Acerca desta questão, o próprio conselheiro de Carlos V, Lorenzo de Carvajal, havia advertido o monarca para ter um cuidado maior com os historiadores que poderiam embelezar as suas obras com superficiais ornamentos retóricos que obscureceriam o objetivo central da história. Cf. KAGAN, Richard. Los cronistas y la corona. La política de la historia en España en las Edades Media y Moderna. Madri: Ediciones Marcial Pons, 2010, p. 103.

${ }^{15}$ De acordo com Walter Mignolo, a partir da segunda metade do século XVI há uma tendência dos escritos espanhóis de abordarem não somente a definição, os fins e a utilidade da história, mas também a estrutura do discurso historiográfico. MIGNOLO, Walter. Cartas, crónicas y relaciones del descubrimiento y la conquista. In: ÍNIGGO MADRIGAL, Luis. (coord.). Historia de la literatura hispanoamericana. Época colonial. Madri: Cátedra, 1982.

${ }^{14}$ LÓPEZ DE GÓMORA, Francisco. Historia de la conquista de Mexico. Venezuela: Ayacucho, 1979, p. 4.

${ }^{15}$ PRIETO, Andrés. "De rebus gestis Ferdinandi Cortesii" y la "Conquista de México": algunas consideraciones en torno a la metodologia histórica de Francisco López de Gómora. In: REGALADO DE HURTADO, Liliana \& SOMEDA, Hidefugi (coord.). Construyendo historias: aportes para la historia hispano-americana a partir de las crónicas. Lima: PUCP, 2005, p. 22.

${ }^{16}$ LÓPEZ DE GÓMORA, Francisco. Historia de la conquista de Mexico, op. cit., 1979, p. 1.
} 
o leitor dissimule os possíveis erros e faltas da sua narração, considerando, pois, que as falhas não decorrem de malícia ou artimanhas, mas, sim, da própria dificuldade do fazer histórico ${ }^{17}$ (LÓPEZ DE GÓMORA, 1979, p. 4).

Diego Fernández de Palencia, nomeado cronista do Peru em 1555, também aborda no proêmio da sua obra a maneira correta de se narrar o passado. Nas primeiras páginas de sua Historia del Peru, datada de 1571, ao comentar o propósito educativo da história, lembrando que ela é a testemunha dos tempos e a mensageira fiel de toda a Antiguidade, assinala o compromisso que aqueles que querem transmitir os eventos do passado devem ter com a escrita da verdade. De acordo com Palencia, esse compromisso seria alcançado se os historiadores selecionassem as suas fontes e, como ele, procurassem trazer à luz o que haviam investigado corretamente sem o receio de desagradar a uns e outros com os conteúdos apresentados ${ }^{18}$ (FERNÁNDEZ DE PALENCIA, 1571, f. 4r). Dito de outro modo, esse cronista sugere que aqueles que se dispunham a escrever o passado deveriam fazê-lo sem o receio das diversas e contrárias opiniões que poderiam partir de quem se colocasse contrário às matérias narradas na sua história ${ }^{19}$ (FERNÁNDEZ DE PALENCIA, 1571, f. 4r). Quanto ao estilo apropriado para a narrativa dos fatos, embora esse cronista não forneça conselhos de como escrever os eventos tal como fizeram outros cronistas em suas obras, alega que a sua história foi feita com frases simples a fim de não ir além do que o seu talento alcança deixando ao leitor a opção de corrigir e emendar suas eventuais faltas ${ }^{20}$ (FERNÁNDEZ DE PALENCIA, 1571, f. 5v).

Apresentando argumentos semelhantes aos utilizados por Fernández de Palencia, frei Juan de Torquemada também registra, na Monarquia indiana - publicada em Sevilha, em 1615 - o seu parecer sobre as regras específicas para a produção da história e os procedimentos que devem seguir os historiadores que exercem esse ofício. ${ }^{21}$ No prólogo geral dessa obra, defende

\footnotetext{
17 Ibidem, p. 4.

${ }^{18}$ FERNÁNDEZ DE PALENCIA, Diego. Historia del Peru. Sevilha: Casa de Hernando Díaz, 1571, f. 4r.

19 Ibidem, f. 4v.

${ }^{20}$ Ibidem, f. 5v.

${ }^{21}$ De acordo com Miguel León-Portilla, a obra de Juan de Torquemada vale tanto por investigar "el pasado prehispánico de México al igual que la significación del choque de la conquista, la implantación de nuevas instituciones y la historia del primer siglo de vida novohispana" como pelo "señalamiento de las fuentes que se valió y el análisis de su concepto de la historia". LEÓN-PORTILLA, Miguel. Biografía de Juan de Torquemada. In: TORQUEMADA, Juan de. Monarquía indiana. México: Unam, Instituto de Investigaciones Históricas, 1975-1986. Disponível em: http://www.historicas.unam.mx/ publicaciones/publicadigital/monarquia/volumen/07/miv7003. Acesso em: 13 jul. 2018, p. 48.
} 
que, sendo a história um benefício imortal que oferece aos homens "as coisas passadas, como um testemunho e argumento para as vindouras", aquele que se dispõe a escrevê-la deve ter muito trabalho para cumprir essa difícil tarefa $^{22}$ (TORQUEMADA, 1615, p. 5). E acrescenta:

Escrever história de verdades não é tão fácil como alguns pensam. É necessário, além de outras mil coisas, uma diligência grande na inquisição das coisas verdadeiras, um amadurecimento não menor em conferir as duvidosas e em computar os tempos, uma prudência particular e assinalada em tratar uma e outra e, sobretudo, na era que estamos, é necessário ter ânimo e desembaraço para pretender agradar só a Deus, sem aguardar dos homens o prêmio (ou algum interesse) (...) (23 (TORQUEMADA, 1615, p. 5).

Desdobrando melhor seu posicionamento, esse cronista argumenta mais detidamente no prólogo ao primeiro livro - que, "como a história pede a verdade, é necessário que o historiador não se afaste dela e que diga logo o que sabe"24 (TORQUEMADA, 1615, p. 2) com base nas fontes que pôde reunir. ${ }^{25}$ Avançando um pouco mais do que haviam proposto os outros cronistas, o autor da Monarquia indiana sugere que os escritores sigam as diligências necessárias para alcançar as matérias que se dispõem a narrar em suas histórias. No seu caso particular, para contar o passado mexicano e os acontecimentos ocorridos após a chegada dos espanhóis, tema central da sua obra, declara ter juntado e conferido os papéis e memoriais, bem como inquirido e investigado a verdade sobre o que escreveram pessoas fidedignas e recuperado relações e testemunhos certos de escrivães e arquivos de mosteiros ${ }^{26}$ (TORQUEMADA, 1615, p. 4).

Esses procedimentos ditados por Torquemada e por seus coetâneos, que buscavam transmitir o que avaliavam ser a verdade sobre os eventos passados, repercutem os ensinamentos deixados por Cícero a respeito da exatidão da história. ${ }^{27}$ De acordo com o cronista, o autor latino preconizava que "a

\footnotetext{
${ }^{22}$ TORQUEMADA, Juan de. Prólogo geral. In: Idem. Monarquia indiana. Sevilha, 1615, p. 5.

${ }^{23}$ Idem, p. 5. Grifos meus.

${ }^{24}$ Ibidem, p. 2.

${ }^{25}$ Richard Kagan avalia que os historiadores desse período estavam "plenamente comprometidos con la imagen de la historia de Cicero como lux veritas" e que embora cientes das dificuldades de se descobrir a verdade julgavam que poderiam desvendá-la se averiguassem "con rigor la fiabilidad de las fuentes, comprobase una y otra vez la veracidade de las evidencias de que disponía y finalmente escribiera una historia que su audiencia considerase de utilidad". KAGAN, Richard. Los cronistas y la corona ..., op. cit., 2010, p. 26.

${ }^{26}$ TORQUEMADA, Juan de. Prólogo geral, op. cit., 1615, p. 4.

${ }^{27}$ Não só Cicero aparece como uma referência importante nesses escritos elaborados no período renascentista. Nomes como Tucídides, Tácito e Políbio também são modelos para esses letra-
} 
história, diferentemente da poesia, que pretende deleitar o leitor com o gosto da linguagem, resguarda a pontualidade da verdade"28 (TORQUEMADA, 1615, p. 2). O historiador, não podendo fingir ou fantasiar tal como o poeta, deve procurar contar os fatos sem se comprometer em demasia com as formas do texto, pois a sua matéria, ao contrário da poesia, tem como finalidade instruir através da narrativa de eventos verdadeiros. ${ }^{29} \mathrm{Na}$ altura da obra em que procura explicar o estilo que devem adotar os historiadores, Torquemada parte dessa diferença entre a história e a poesia para alertar sobre as armadilhas que podem surgir dos usos exagerados de recursos estilísticos no texto. Para ele, a eloquência do texto não pode ser um artifício para os historiadores se desviarem da verdade como fazem os poetas, pois o ornamento das frases, conforme aponta, não deve ser o objetivo que os motiva a escrever, mas, sim, um recurso utilizado para tornar as suas obras mais aprazíveis ao leitor. ${ }^{30}$

Tal preocupação com a forma do texto está, contudo, mais presente nos relatos elaborados no século XVII, momento em que os cronistas de Índias passam a expressar uma maior atenção às regras que ordenavam a escrita da história. ${ }^{31}$ A Historia de la conquista de México, por exemplo, composta, em 1684, pelo historiador Antonio de Solís, é um dos relatos em que essa atenção voltada para a composição do texto está mais bem colocada. Nas primeiras linhas do prólogo, ao apresentar o tema e os motivos que o levaram a abordá-lo, esse cronista não deixa de comentar a maneira como elaborou a sua história. Demonstrando cuidado com a veracidade dos fatos, escreve

dos na produção de suas obras. Cf. MOMIGLIANO, Arnaldo. As raízes clássicas da historiografia moderna. São Paulo: Edusc, 2004.

${ }^{28}$ TORQUEMADA, Juan de. Prólogo geral, op. cit., 1615, p. 2.

${ }^{29}$ De acordo com María José Vega, aqueles que se propunham a escrever sobre os acontecimentos passados "no sólo se acogen al prestigio de la historia como arte mayor, sino también a sus protocolos de indagación y escritura, al modo de adquirir conocimientos y conferir testimonios, al uso de fuentes documentales y a la interrogación de testigos, al concepto, pues, de la verdad histórica como producto del método y del estudio". JOSÉ VEGA, María E VILÀ, Lara. La teoría de la épica en el siglo XVI (España, Francia, Italia y Portugal). Espanha: Editorial Academia del Hispanismo, 2010, p. 111.

30 Segundo Victoria Pineda, a relação da história com outras disciplinas próximas como a poesia, a oratória e a retórica foi "tema predominante y caracterizante de la primera etapa de las artes de la historia, etapa que iría desde finales del siglo XIV hasta pasada la mitad del XVI. La cuestión irá perdiendo vigencia a medida que la historia vaya adquiriendo la autonomía a la que aspira y vaya siendo contemplada en sí misma o, a lo sumo, en conexión con otros campos diferentes". PINEDA, Victoria. La poesía de los historiógrafos. Bulletin Hispanique, vol. 117, n. 1, Bordeaux, jun. 2015, p. 25-42, p. 30. ISSN 17753821. Disponível em: https://journals.openedition.org/bulletinhispanique/. Acesso em: 24 out. 2017. DOI: https://journals.openedition.org/bulletinhispanique/3722.

${ }^{31}$ IGLESIA, Ramón. Cronistas e historiadores de la conquista de Mexico. México: Biblioteca de la Ciudad de México, s/d, p. 251. 
que muitas vezes retornou à tarefa de consultar livros e papéis para obter a pontualidade da notícia que pretendia narrar² (SOLIS, 1985, p. 23).

Já ao se referir à disposição da escrita ou, segundo suas próprias palavras, ao "estilo que devem seguir os historiadores", Solís discorre sobre os critérios estilísticos empregados na composição da sua obra argumentando que se pautou pelos autores mais importantes e se cercou dos termos "mais rigorosos da língua castelhana", que considerava necessários para "adocicar o útil da oração"33 (SOLIS, 1985, p. 23-24) Discorrendo mais especificamente sobre o modo como deveriam escrever os historiadores, esse cronista recomenda o uso de três estilos para assegurar a harmonia na narrativa: o estilo humilde ou familiar para contar os sucessos; o estilo moderado para explicar as resoluções e os desfechos dos eventos; e, finalmente, o estilo sublime ou mais elevado, peculiar aos poetas, para descrever as províncias e os lugares onde sucederam os acontecimentos ${ }^{34}$ (SOLIS, 1985, p. 24).

Ao propor um conjunto de regras que deveriam conduzir a narrativa do passado, Solís expressa a preocupação na época de promover uma escrita mais apurada e que estivesse comprometida com certas diretrizes recomendadas para a composição da história. Uma preocupação manifestada também por outros autores que escreveram nos séculos XVI e XVII e que reservaram páginas de suas obras - como novelas, relações e tratados de história - para refletirem sobre essa matéria ${ }^{35}$ (O'GORMAN, 1985, p. x). São os autores que compuseram os tratados de história, contudo, aqueles que apresentam de maneira mais significativa os fundamentos necessários ao labor histórico e os requisitos exigidos do historiador. ${ }^{36}$ Escrevendo tanto em latim como em castelhano, figuras como Juan Páez de Castro, Sebastián Fox Morcillo, Juan Costa, Luis Cabrera de Córdoba e Jerónimo de San José para citarmos alguns nomes - tiveram como meta definir o gênero histórico e instruir sobre o modo mais correto de promover a sua escrita. Para eles, a boa reputação de uma monarquia estava diretamente vinculada à tarefa

\footnotetext{
32 SOLÍS, Antonio de. Historia de la conquista de Mexico. México: Editorial Porrúa, 1985, p. 23.

33 Ibidem, p. 23-24.

${ }^{34}$ Ibidem, p. 24.

35 O'GORMAN, Edmundo. Estudio preliminar. In: SOLÍS, Antonio de. Historia de la conquista de México. México: Editorial Porrúa, 1985, p. X.

${ }^{36}$ COURCELLES, Dominique de. Escribir la historia, escribir historias en el mundo hispánico. México: Unam, Instituto de Investigaciones Históricas, 2009, p. 270.
} 
de historiadores que soubessem registrar com verdade e maestria os feitos louváveis dos governantes. ${ }^{37}$

O cronista oficial de Carlos V, Juan Páez de Castro, apresenta, no Memorial de las cosas necesarias para escribir historia (1557), uma das primeiras orientações para narrar os eventos passados. Nas páginas que integram esse pequeno tratado, escrito após encontrar dificuldades para definir o método utilizado na sua narrativa sobre a Espanha, o cronista esclarece que escrever história "não é contar o que se passou" assim como fazem as amas com as crianças, mas apontar o tempo e o lugar em que os acontecimentos ocorreram, explicar as causas que levaram ao início, narrar os meios empregados pelos homens para se obter o desfecho esperado e mencionar os acertos e os erros cometidos nessas ações ${ }^{38}$ (PÁEZ DE CASTRO, 2009, p. 321). Para que seja possível essa escrita, sugere Páez de Castro, é necessário que o historiador atente não só aos fatos, mas também procure informar-se de diferentes formas, conforme descreve a seguir:

(...) primeiramente ver toda a Espanha com curiosidade fazendo memoriais do espaço para poder pintar os lugares onde se passaram as coisas (...), ir tomando relações de pessoas antigas e diligentes, ler as memórias de pedras públicas e letreiros de sepulturas, desenvolver registros antigos de notários onde se encontram pleitos de estados, testamentos de reis e grandes homens, processos de duelos e outras muitas coisas que fazem a história, revirar bibliotecas de colégios, mosteiros e abadias, ver os arquivos de muitas cidades para saber seus privilégios e dotações próprios, seus foros e ordenanças; inquirir as linhagens que há em cada uma e saber suas descendências e brasões $(. . .)^{39}$ (PÁEZ DE CASTRO, 2009, p. 321).

Mas essa busca por vestígios que possam ajudar na reconstrução dos eventos do passado não é suficiente, já que Páez de Castro também considera importante que esses escritores tenham conhecimentos em outras disciplinas ao compor os seus relatos. Em um extenso parágrafo, aponta a necessidade de se saber filosofia natural para explicar melhor as causas de certos

\footnotetext{
37 Acerca dessa questão, Fernando Sánchez Marcos destaca nessa época uma "fuerte vinculación de la historia con el poder monárquico, por lo que podemos, metafóricamente y en sentido lato, hablar de Clío en la corte". SÁNCHEZ MARCOS, Fernando. La historiografía en la Edad Moderna. In: ANDRÉS-GALLEGO, José (coord.). Historia de la historiografía española. Madri: Ediciones Encuentro, 1999, p. 120.

${ }^{38}$ PÁEZ DE CASTRO, Juan. Método para escribir la historia. Anexo. In: COURCELLES, Dominique de. Escribir la historia, escribir historias en el mundo hispánico. México: Unam, Instituto de Investigaciones Históricas, 2009, p. 321.

39 Ibidem, p. 321. Grifos meus.
} 
acidentes não provados pelos homens, tais "como os dilúvios, as secas, os incêndios, as tempestades, as novas doenças do corpo" ${ }^{\prime \prime 0}$ (PÁEZ DE CASTRO, 2009, p. 321) Além disso, julga imprescindível conhecer "os povos, os montes, os rios e mares, os portos, as praias e as ilhas para saber pintar as partes onde se passaram os eventos" ${ }^{\prime \prime 1}$ (PÁEZ DE CASTRO, 2009, p. 322) Prosseguindo com essa argumentação, o cronista ainda escreve ser conveniente saber geometria, não somente para "medir as alturas e as distâncias dos lugares", mas para dizer "as causas que explicam os engenhos e as máquinas que cada dia se inventam e os que antigamente se usavam" e para poder contar sem erros "a extensão dos lugares, ilhas e terra firme" Tudo isso basta para mostrar, declara esse cronista, que escrever história "não é coisa tão fácil e ligeira como se pensa" ${ }^{\prime \prime 3}$ (PÁEZ DE CASTRO, 2009, p. 327).

Quanto ao estilo que deve ser adotado pelos historiadores na composição da obra, esse cronista é direto ao afirmar que a narrativa não pode ser nem simples nem tampouco entoada para que seja lida "ao som de trombeta como diziam os versos de Homero" ${ }^{\prime 44}$ (PÁEZ DE CASTRO, 2009, p. 317). Para ele, a boa escrita da história deve ser extensa, "abundante e com um descuido natural para parecer que as coisas já estavam ditas" e, junto com isso, fluida para que o conteúdo escrito deleite e distraia o leitor "como o ar fresco desejado no verão (...), naturalmente puro e limpo" 45 (PÁEZ DE CASTRO, 2009, p. 320). Mas, adverte ele, é preciso utilizar a eloquência ao "enaltecer e elogiar o bem feito" e ao "abater e reprovar o mal feito", já que da história "saem os exemplos que têm grande força nas ações" dos homens" (PÁEZ DE CASTRO, 2009, p. 320).

De forma complementar, o historiador do reinado de Felipe II, Luiz Cabrera de Córdoba, reflete, no tratado De historia para entenderla y escribirla, publicado em 1611, outros princípios que devem guiar a transmissão do passado, tais como a diferenciação entre o gênero histórico e o poético ${ }^{47}$ (STOLL, 1998, p. 150). Conforme especifica a singularidade do discurso histórico, ele avalia que os limites da ação do historiador para a composição do texto são muito

\footnotetext{
${ }^{40}$ Ibidem, p. 321.

${ }^{41}$ Ibidem, p. 322.

${ }^{42}$ Ibidem, p. 327.

43 Ibidem, p. 327.

${ }^{44}$ Ibidem, p. 317.

${ }^{45}$ Ibidem, p. 320.

${ }^{46}$ Ibidem, p. 320.

47 STOLL, Eva. Géneros en la historiografía indiana: modelos y transformaciones. In: OESTERREICHER, Wuff; STOLL, Eva; WESCH, Andreas. Competencia escrita, tradiciones discursivas y variedades linguísticas: aspectos del español europeo y americano en los siglos XVI y XVII. Tübingen: Narr, 1998, p. 150.
} 
mais delimitados do que os do poeta. Segundo sua obra, enquanto este tem a permissão para fantasiar, elevar ou diminuir os feitos, adorná-los e narrar as coisas "como haviam de ser e não como foram", supondo fatos "sem semelhança com a verdade" para que pareçam ser mais ilustres, o historiador, ao contrário, tem de prosseguir fielmente com as matérias que conta sem alterá-las, narrando com ornamento e gala como elas são e não como lhe convém ${ }^{48}$ (CABRERA DE CÓRDOBA, 1948, p. 27). A história, segundo Cabrera de Córdoba, é por isso mais regular nas palavras e nas sentenças e tem mais do honesto e do exemplar do que o texto da poesia ${ }^{49}$ (CABRERA DE CÓRDOBA, 1948, p. 28).

Por essa razão, explica ele que nem todos os escritores dedicados à tarefa de compor histórias conseguem atingir seus objetivos, pois os escritores vulgares contentam-se em dizer a verdade acerca dos sucessos sem destacarem a ética e a política nesses fatos. Já os demais escritores, por não se preocuparem com a fidelidade dos eventos que narram, cuidam somente da elegância artificial do texto para atrair leitores. Retomando uma metáfora utilizada pelo historiador grego Políbio, esse tratadista declara que a história feita desta maneira é como uma "donzela formosa em suas feições", mas que lhe faltam os olhos e, entre outros defeitos, tem "manchas, verrugas e buracos no rosto"50 (CABRERA DE CÓRDOBA, 1948, p.30). Para ele, a "pura e limpa notícia das coisas, sem interesse nem obediências, é a luz e a alma da história e a virgindade dessa donzela" ${ }^{51}$ (CABRERA DE CÓRDOBA, 1948, p. 30) que, se escrita corretamente, encanta a todos.

Além da exigência de uma história que seja feita a partir de um conjunto de regras, Cabrera de Córdoba lista outros requisitos necessários para a boa escrita dessas obras. A exemplo de Páez de Castro, esse autor prescreve uma série de qualidades que precisam ter aqueles que se dedicam a narrar o passado. Diz ele:

Há de saber boas letras, ter lição nas divinas, ser douto em antiguidades, prático no mundo e que o tenha percorrido, exercitado em todas as matérias, principalmente de Estado, inteligente nas coisas da guerra, homem cortês, versado nos negócios públicos e governos de reinos, províncias e povos, inquiridor dos feitos ocultos, cheio de sentenças e ditos graves, instruído em exemplos, erudito, eloquente, grave, inteiro, severo, urbano,

\footnotetext{
${ }^{48}$ CABRERA DE CÓRDOBA, Luis. De historia para entenderla y escribirla. Edição, estudo preliminar e notas de Santiago Montero Díaz. Madri: Instituto de Estudios Políticos, 1948, p. 27.

49 Ibidem, p. 28.

50 Ibidem, p. 30

51 Ibidem, p. 30.
} 
diligente, medido, estudioso (...), conhecedor do bom e do mau que há nos escritores, com perfeita prudência tanto no dizer quanto no calar, moderado em seus afetos, que tenha boa escolha de tudo, fortaleza e ânimo para dizer a verdade e seu parecer, igualdade em contar as coisas dignas de ser louvadas ou repreendidas ${ }^{52}$ CABRERA DE CÓRDOBA, 1948, p. 30).

Direcionando sua fala aos escritores, esse tratadista declara que se todos soubessem quantos são os atributos exigidos e entendessem bem a dificuldade de praticá-los não haveria tantos imprudentes a ser e a querer ser historiadores. Suas prédicas mostravam-se de acordo com as orientações ditadas por outros tratadistas que também dissertaram sobre quem poderia levar adiante a tarefa de escrever sobre os fatos do passado.

Quanto ao método empregado na composição da história, Cabrera de Córdoba recomenda a consulta de muitos testemunhos para evitar que a narração fique restrita às observações de um único autor. Segundo ele, melhor seria a variação de conteúdos e de argumentos prováveis sobre determinado fato, cabendo ao historiador verificar a verdade ou o mais verossímil que ele possa alcançar ${ }^{53}$ (CABRERA DE CÓRDOBA, 1948, p. 24). No que tange à forma do texto, a receita seria optar por um estilo livre, "mais cheio de boas razões e sentenças do que de cores e figuras retóricas", já que o alvo do historiador é "deleitar com a elegância e ordem de palavras", persuadindo a seguir "o bem e a apartar do mal no momento em que ensina com a variedade dos sucessos, conselhos e modos de executá-los" ${ }^{\prime \prime 5}$ (CABRERA DE CÓRDOBA, 1948, p. 124). Em razão dessas regras, é recomendável, de acordo com esse tratadista, que o escritor tenha "boa gramática" e saiba ordenar as palavras no texto, utilizando termos correntes a fim de facilitar a compreensão do leitor ${ }^{55}$ (CABRERA DE CÓRDOBA, 1948, p. 125).

Semelhantes lições são melhor definidas no tratado Genio de la historia, de 1650, composto pelo religioso da ordem carmelita Jerónimo de San José. Dividida em três partes, a obra elucida o que esse autor considerou ser o genio ou a arte da história, isto é, as regras próprias para a produção desse saber. Partindo da definição de que a história é uma "narração plana de casos e coisas verdadeiras", ${ }^{56}$ (SAN JOSE, 1768, p. 37) composta para dar

\footnotetext{
52 Ibidem, p. 30.

53 Ibidem, p. 24.

${ }^{54}$ Ibidem, p. 124

55 Ibidem, p. 125

56 SAN JOSÉ, Genio de la historia. Madri: Imprenta de Don Muñoz del Valle, 1768, p. 37.
} 
conselhos e avisos aos homens do presente, esse autor busca mostrar como escrever os fatos de forma bem ordenada. Propondo um método para guiar os historiadores, esse tratadista assinala, entre outros elementos, não apenas o estilo do texto e a linguagem a ser empregada, mas também os requisitos que julgava indispensáveis aos escritores que desempenhavam esse ofício ${ }^{57}$ (VIDAL, 2009, P. 140). Na terceira parte da obra, por exemplo, indica como proceder quando os assuntos abordados são recentes ou de um tempo remoto: no caso dos acontecimentos recentes, escreve que há uma "imensa dificuldade para a averiguação" porque é grande a variedade de testemunhos, sendo necessário, portanto, "procurar os mais fiéis, dados por pessoas mais advertidas, desapaixonadas e de mais crédito e autoridade" ${ }^{\prime \prime 58}$; (SAN JOSE, 1768, p. 129) já no que se refere à narrativa dos assuntos passados, considera ser mais dificultoso ainda "lutar com sombras e espectros" para resgatar os "sucessos esquecidos"59 (SAN JOSE, 1768, p. 130). A sua receita para recolher os vestígios de outra época, ou melhor, os acontecimentos "cuja memória de quase tudo pereceu", está na atuação do historiador de "prognosticar [tais vestígios], juntá-los, uni-los, encaixá-los, dando a cada um seu ajuste, lugar e próprio assento na disposição e no corpo da história"60 (SAN JOSE, 1768, p. 131). Tratando especificamente do estilo da escrita, esse autor recomenda conciliar o estilo supremo, que utiliza palavras e vocábulos mais suntuosos nas orações com o objetivo de chamar a atenção do leitor, e o estilo ínfimo, que emprega frases ordinárias e vulgares para equilibrar o texto. ${ }^{61}$

Para desempenhar tal tarefa de reconstituir o passado, Jerónimo de San José, a exemplo de Luis Cabrera de Córdoba, ainda pontua uma série de requisitos necessários para o historiador. Primeiramente, recomenda que para escrever é necessário ser sábio e ter notícia universal das "diferentes artes, ciências e faculdades que podem conduzir ao maior decoro, luz e ornato do

\footnotetext{
${ }^{57}$ Cf. VIDAL, Silvina Paula. El arte histórica en la España del siglo XVII: Jerónimo de San José y el Genio de la historia (1651). In: Artes, Ciencias y Letras en la America Colonial: investigaciones presentadas en el Simposio Internacional Homónimo realizado en Buenos Aires los días 23, 24 y 25 de noviembre de 2005, vol. 2. Buenos Aires: Teseo. Biblioteca Nacional, 2009, p. 140.

${ }^{58}$ SAN JOSÉ, Jerónimo de. Genio de la historia, op. cit., 1768, p. 129.

59 Ibidem, p. 130.

${ }^{60}$ Ibidem, p. 131.

${ }^{61}$ Para Victoria Pineda, "esa concatenación de los tres estilos, que se determinan de alguna manera entre sí, le sirve a fray Jerónimo para, en un sugestivo giro, encarecer la dificultad de alcanzar un buen estilo histórico por el encumbramiento a que ha llegado el estilo poético y retórico en España". PINEDA, Victoria. La poesía de los historiógrafos, op. cit., 2015, p. 38.
} 
que se escreve"62 (SAN JOSE, 1768, p. 124). Sustenta que esse compromisso de escrever bem seria obrigação daqueles que eram imbuídos da tarefa de contar o que havia, o que se passava e o que sucedia no mundo. Dando sequência às suas instruções, esse religioso destaca a diligência como um requisito fundamental dos escritores de história, pois, para ele, é essa qualidade que impede que os historiadores se deixem governar pelas paixões pessoais nos seus textos. Jerónimo de San José argumenta ser mais conveniente que os historiadores não se encontrem presentes nos sucessos que se dispõem a narrar porque, sem opinião particular sobre os fatos, ficam mais livres para julgá-los e transmiti-los de acordo com a verdade. Em diálogo com os preceitos em voga nessa época, o autor aconselha que o rigor histórico se sobreponha às paixões para não permitir "nem que o amor e o ódio governem a pena [do historiador] e tampouco que a esperança e o medo a tiranizem"63 (SAN JOSE, 1768, p. 170).

Assim como Jerónimo de San José, outros tratadistas e também cronistas de Índias visavam certificar que o oficio do historiador seria conduzido por regras bastante delimitadas, de forma que suas obras pudessem ser vistas como um grande espelho em que se reluzia a imagem clara e límpida do passado. Esse conjunto de autores aqui tratados buscavam criar um método para a escrita da história tão rigoroso quanto o que já pautava a produção de outras disciplinas próximas, como a retórica e a poesia. É possível afirmar, assim, que a série de obras aqui abordada revela a ambição de uma época de disciplinar não apenas a escrita, estabelecendo critérios próprios do fazer histórico, mas também o próprio historiador, já que este era alvo de inúmeros conselhos a respeito da maneira como deveria se portar no âmbito de sua atividade.

Embora não seja possível saber o público leitor que esses tratados alcançaram no contexto em que foram produzidos, especialmente o público composto pelos cronistas de Índias, suas páginas tocam em temas pertencentes a um mesmo universo partilhado pelos espanhóis que escreveram nesse período. Mais precisamente, a definição da história e das normas que ditavam a sua escrita - tais como o estilo para a composição do texto, o rigor com as fontes e as qualidades necessárias ao historiador - também são temas que vinham sendo trabalhados, ainda que de maneira menos expressiva, nos prólogos ou proêmios de outras obras elaboradas nesse período. Pode-se dizer, dessa forma, que tanto esses tratados como os demais textos produ-

\footnotetext{
${ }^{62}$ SAN JOSÉ, Jerónimo de. Genio de la historia, op. cit., 1768, p. 124.

63 Ibidem, p. 170.
} 
zidos na Espanha, isto é, as crônicas da conquista americana e as histórias gerais, ajudaram a definir um mesmo saber sobre a história e a escrita da história elaborada em terras hispânicas nessa época.

\section{Referências bibliográficas}

\section{Fontes primárias}

CABRERA DE CÓRDOBA, Luis. De historia para entenderla y escribirla. Madri: Instituto de Estudios Políticos. Edição, estudo preliminar e notas de Santiago Montero Díaz, 1948.

FERNÁNDEZ DE PALENCIA, Diego. Historia del Peru. Sevilha: Casa de Hernando Díaz, 1571.

LAS CASAS, Bartolomé de. Historia de las Indias, tomo I. Venezuela: Biblioteca Ayacucho, 1986.

LÓPEZ DE GÓMORA, Francisco. Historia de la conquista de Mexico. Venezuela: Ayacucho, 1979.

PÁEZ DE CASTRO, Juan. Método para escribir la historia. Anexo. In: COURCELLES, Dominique de. Escribir la historia, escribir historias en el mundo hispánico. México: Unam, Instituto de Investigaciones Históricas, 2009.

SAN JOSÉ, Jerónimo de. Genio de la historia. Madri: Imprenta de Don Muñoz del Valle, 1768.

SOLÍS, Antonio de. Historia de la conquista de Mexico. México: Editorial Porrúa, 1985. TORQUEMADA, Juan de. Monarquia indiana. Sevilha, 1615.

\section{Fontes secundárias}

ARAGÜÉS ALDAZ, José. Deus concionator. Mundo predicado y retórica del exemplum en los siglos de oro. Amsterdam: Atlanta, 1999.

CERVANTES SAAVEDRA, Miguel de. El ingenioso hidalgo don Quijote de la Mancha. Edição de Enrique Suárez Figaredo. Lemir 19. Conmemoración del IV Centenario de la Segunda Parte del Quijote, 2015.

CORTIJO OCAÑO, Antonio. Creación de una voz de autoridad en Bartolomé de Las Casas: estudio del "Prólogo" de la Historia de Indias. Revista Iberoamericana, vol. LXI, n. 170-171, jan.-jun. 1995, p. 291-229. ISSN 2154-4794. Disponível em: http://revista-iberoamericana.pitt.edu/ojs/index.php/Iberoamericana/issue/ view/252. Acesso em: 20 nov. 2017. DOI: http://revistaiberoamericana.pitt.edu/ ojs/index.php/Iberoamericana/article/view/6405/6581.

COURCELLES, Dominique de. Escribir la historia, escribir historias en el mundo hispánico. México: Unam, Instituto de Investigaciones Históricas, 2009. 
CUESTA DOMINGO, Mariano. Los cronistas oficiales de Índias. De López de Velásco a Céspedes del Castillo. Revista Complutense de Historia de América, vol. 33, Madri, 2007, p. 115-150. ISSN 1132-831. Disponível em: http//revistas.ucm.es/index. php/RCHA/. Acesso em: 23 out. 2016. DOI: http://revistas.ucm.es/index.php/ RCHA/article/view/29626.

DURÁN BARCELÓ, Javier. La teoría historiográfica de Bartolomé de Las Casas. Studia aurea. In: III CONGRESO DE LA AISO. Actas, vol. 3. Toulouse, 1996, p. 161-168. ISBN 84-921581-3-1. Disponível em: https://cvc.cervantes.es/literatura/aiso/ pdf/03/aiso 333 021.pdf. Acesso em: 15 dezembro 2017.

GONZÁLEZ BOIXO, José Carlos. Hacia una definición de las crónicas de Indias. Anales de Literatura Hispanoamericana, n. 28, Espanha, 1999, p. 227-238. ISSN 02104547. Disponível em: https://dialnet.unirioja.es/revista/75/A/1999. Acesso em: 13 jun 2015. DOI: https://dialnet.unirioja.es/servlet/articulo?codigo=52307.

IGLESIA, Ramón. Cronistas e historiadores de la conquista de Mexico. México: Biblioteca de la Ciudad de México, s/d.

JOSÉ VEGA, María E VILÀ, Lara. La teoría de la épica en el siglo XVI (España, Francia, Italia y Portugal). Espanha: Editorial Academia del Hispanismo, 2010. Disponível em: http://www.historicas.unam.mx/publicaciones/publicadigital/monarquia/ volumen/07/miv7003Acesso em: 13/07/2018.

KAGAN, Richard. Los cronistas y la corona. La política de la historia en España en las Edades Media y Moderna. Madri: Ediciones Marcial Pons, 2010.

LEÓN-PORTILLA, Miguel. Biografía de Juan de Torquemada. In: TORQUEMADA, Juan de. Monarquía indiana. México: Unam, Instituto de Investigaciones Históricas, 1975-1986. Disponível em: http://www.historicas.unam.mx/publicaciones/publicadigital/monarquia/volumen/07/ miv7003. Acesso em: 13 jul. 2018.

IGNOLO, Walter. Cartas, crónicas y relaciones del descubrimiento y la conquista. In: ÍÑIGO MADRIGAL, Luis. (coord.). Historia de la literatura hispanoamericana. Época colonial. Madri: Cátedra, 1982.

MOMIGLIANO, Arnaldo. As raízes clássicas da historiografia moderna. São Paulo: Edusc, 2004.

MONTERO DÍAZ, Santiago. La doctrina de la historia en los tratadistas del siglo de oro. In: CABRERA DE CÓRDOBA, Luis. De historia para entenderla y escribirla. Madri: Instituto de Estudios Politicos, 1948.

O'GORMAN, Edmundo. Cuatro historiadores de Indias. Siglo XVI. México: Sep/ Setentas, 1972.

O'GORMAN, Edmundo. Sentido y actualidad de la historia de la conquista de Mexico de Antonio de Solís. In: SOLÍS, Antonio. Historia de la conquista de Mexico. México: Editorial Porrúa, 1985.

PINEDA, Victoria. La poesía de los historiógrafos. Bulletin Hispanique, vol. 117, n. 1, Bordeaux, jun. 2015, p. 25-42. ISSN 1775-3821. Disponível em: https://journals.openedition.org/bulletinhispanique/. Acesso em: 24 out. 2017. DOI: https://journals.openedition.org/bulletinhispanique/3722. 
PORQUERAS MAYO, Alberto. El prólogo como genero literario. Su estudio en el siglo de oro español. Madri: Consejo Superior de Investigación Científica, 1957.

PRIETO, Andrés. "De rebus gestis Ferdinandi Cortesii" y la "Conquista de México": algunas consideraciones en torno a la metodologia histórica de Francisco López de Gómora. In: REGALADO DE HURTADO, Liliana $\mathcal{E}$ SOMEDA, Hidefugi (coord.). Construyendo historias: aportes para la historia hispano-americana a partir de las crónicas. Lima: PUCP, 2005.

SANCHÉZ MARCOS, Fernando. La historiografía sobre la Edad Moderna. In: ANDRÉS-GALLEGO, José (coord.). Historia de la historiografia española. Madri: Encuentro, 1999.

STOLL, Eva. Géneros en la historiografía indiana: modelos y transformaciones. In: OESTERREICHER, Wuff; STOLL, Eva; WESCH, Andreas. Competencia escrita, tradiciones discursivas y variedades linguísticas: aspectos del español europeo y americano en los siglos XVI y XVII. Tübingen: Narr, 1998.

VIDAL, Silvina Paula. El arte histórica en la España del siglo XVII: Jerónimo de San José y el Genio de la historia (1651). In: Artes, Ciencias y Letras en la America Colonial: investigaciones presentadas en el Simposio Internacional Homónimo realizado en Buenos Aires los días 23, 24 y 25 de noviembre de 2005, vol. 2. Buenos Aires. Teseo: Biblioteca Nacional, 2009. 